www.nature.com/mp

\title{
CORRIGENDUM
}

\section{HPA axis genetic variation, cortisol and psychosis in major depression}

AF Schatzberg, J Keller, L Tennakoon, A Lembke, G Williams, FB Kraemer, JE Sarginson, LC Lazzeroni and GM Murphy

Molecular Psychiatry (2014) 19, 1151; doi:10.1038/mp.2014.57; published online 27 May 2014

Correction to: Molecular Psychiatry (2014) 19, 220-227; doi:10.1038/mp.2013.129

In footnote a in Table 1 ('Less than five total in the rare homozygous, collapsed into the heterozygous SNP group'), the number 'five' should have been 'four'.
In addition, there were errors in Supplementary Table S1, in the rows for $\mathrm{CRH}-\mathrm{R} 2$ and $\mathrm{Nr} 3 \mathrm{C} 2$ (MR). The corrected supplementary table can be accessed via the online version of this corrigendum.

The errors do not affect the main results or discussion section of the article.

Supplementary Information accompanies the paper on the Molecular Psychiatry website (http://www.nature.com/mp) 